\title{
A comparative study of selenium concentration and glutathione peroxidase activity in normal and breast cancer patients
}

\author{
Masoumeh Moradi ${ }^{1, *}+$, Mohammad Hassan Eftekhari ${ }^{1}$, Abdolrasoul Talei ${ }^{2}$ and \\ Abdolreza Rajaei Fard ${ }^{3}$ \\ ${ }^{1}$ Department of Nutrition, School of Health, Shiraz University of Medical Sciences, Shiraz, Iran: ${ }^{2}$ Department of \\ Surgery, School of Health, Shiraz University of Medical Sciences, Shiraz, Iran: ${ }^{3}$ Department of Biostatistics, \\ Shiraz University of Medical Sciences, Shiraz, Iran
}

Submitted 8 May 2007: Accepted 5 January 2008: First published online 7 March 2008

\begin{abstract}
Objective: The present study was undertaken to compare plasma Se values and glutathione peroxidase (GPX) activity in normal and breast cancer patients.

Design: In a case-control study, forty-five breast cancer patients and the same number of healthy women were randomly selected from their population. Se was measured in plasma by atomic absorption spectrophotometry and GPX activity in erythrocytes was measured using a standard spectrophotometric method.

Results: Plasma Se concentration in healthy women and breast cancer patients was in the normal range, with no statistically significant difference observed between the two groups (138.40 (SD 40.36) $\mu \mathrm{g} / \mathrm{l} v .132 \cdot 15$ (SD 35.37) $\mu \mathrm{g} / \mathrm{l}$, respectively). Erythrocyte GPX activity was significantly $(P<0 \cdot 01)$ higher in breast cancer patients $(24 \cdot 81(\mathrm{SD} 11 \cdot 66) \mathrm{U} / \mathrm{g} \mathrm{Hb})$ compared with healthy women $(20 \cdot 29(\mathrm{sD} 4 \cdot 24) \mathrm{U} / \mathrm{g} \mathrm{Hb})$.

Conclusion: The present study indicated that Se deficiency was not a problem in the participants, and sufficient quantity of this element could increase GPX activity to have a protective effect against oxidative damage.
\end{abstract}

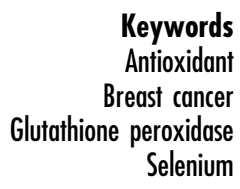

Breast cancer is the most common malignancy in women, with 1 million new cases worldwide each year, and comprises $18 \%$ of female cancers ${ }^{(1)}$. In the Middle East, breast cancer is the most common malignancy among women $^{(2)}$. Similarly in Iran, breast cancer is the highest in rank among cancers of women and accounts for $21.4 \%$ of all malignancies in females ${ }^{(3)}$. There is evidence that Se as an essential trace element has anticancer properties ${ }^{(4-7)}$. Research spanning the last 35 years has established that Se is effective in the reduction of cancer incidence when provided to animals at non-toxic dose (five to ten times the nutritional requirement $)^{(8,9)}$. But for researchers conducting studies on Se and cancer prevention, the most exciting news in recent years has been the finding of Clark et $a l .{ }^{(10)}$ indicating that the supplementation of freeliving people with selenized brewer's yeast decreases overall cancer morbidity and mortality by nearly $50 \%$.

Epidemiological data have also supported a protective effect of Se in man with regard to the prevention of both prostate cancer ${ }^{(11,12)}$ and lung cancer ${ }^{(13)}$. The relationship between Se status and the incidence of breast cancer

$\dagger$ Correspondence address: No. 73, 24 Markazy Alley, South Sazman Barnameh Street, Ferdos Boulevard, Sadegiye Square, Tehran, Iran. needs to be clarified, however, because one study indicates a protective effect ${ }^{(14)}$ whereas other studies have not shown any protective effect ${ }^{(15-18)}$.

Cellular oxidative damage is a well-established general mechanism for cell and tissue injury. Oxidative damage to cells is caused primarily by free radicals and reactive oxygen species. Free radicals have the ability to bind to most normal cellular components; they react with unsaturated bonds of membrane lipids, denature proteins and attack nucleic acids. Prime targets of reactive oxygen species are the PUFA in cell membranes, causing lipid peroxidation which may lead to damage of cellular structure and function ${ }^{(19)}$. Oxidative stress has been suggested to play a role in some physiological conditions and in many disease processes, including carcinogenesis. It has been proposed that Se exerts its chemoprevention effect in different ways, providing a protective effect against oxidative damage by decreasing the amount of free radicals and by increasing the synthesis of glutathione peroxidase $(\mathrm{GPX})^{(4-7)}$. This cytosolic enzyme is the first and best-characterized selenoprotein ${ }^{(20)}$. In the cell cytosol, it functions as an antioxidant by directly reducing $\mathrm{H}_{2} \mathrm{O}_{2}$ and hydroperoxides to the corresponding alcohols and water. Therefore this enzyme can prevent 
the production of reactive oxygen radicals and thus may contribute to protection of the organism's macromolecules and biomembranes against oxidation.

The present study was conducted to compare plasma Se concentration and erythrocyte GPX activity in patients with breast cancer and in healthy women.

\section{Materials and methods}

\section{Participants}

The present study was a hospital-based case-control study. Forty-five women with breast cancer aged 26-70 years (mean 45 (SD 9) years) participated in the study.

The inclusion criteria for the patients were: (i) cases of breast cancer proved by histopathology/cytopathology; (ii) not having undergone any specific treatment for breast cancer; (iii) not suffering from concomitant diseases such as diabetes mellitus, rheumatoid arthritis or thyroid and liver disorders; and (iv) not having taken vitamin or mineral supplements during the past year.

In histopathological analyses, tumours were classified according to the WHO nomenclature classification ${ }^{(21)}$. By this means, eight patients were classified as stage I, twenty-three patients were classified as stage II and fourteen patients were classified as stage III. As a control group, forty-five healthy female volunteers aged 27-67 years (mean 44 (SD 8) years) were selected and included in the study. The last three inclusion criteria mentioned for breast cancer women were considered for healthy subjects as well.

The study protocol and ethical aspects were approved by the ethics committee of the Research Council of the Dean of Research Affairs of Shiraz University of Medical Sciences.

\section{Background characteristics and food consumption assessment}

Data on demographic characteristics, any concurrent illness history, medication, and vitamin and mineral supplementations were collected by interviews. Anthropometry including weight and height were measured for each participant. Body weight was measured to the nearest $0 \cdot 1 \mathrm{~kg}$ using a Seca 713 scale while subjects were minimally clothed. Height was determined using a measuring tape on subjects without shoes. BMI was calculated by dividing weight $(\mathrm{kg})$ by the square of height $\left(\mathrm{m}^{2}\right)$. The food consumption pattern was evaluated by a semiquantitative FFQ. Macro- and micronutrient components were calculated by using Food Processor Software version 1 (Tehran University, Tehran, Iran) modified by incorporating the Iranian food table.

\section{Biochemical analyses}

Blood samples $(5 \mathrm{ml})$ were taken by venous arm puncture and drawn into EDTA tubes. Plasma was separated by centrifugation at $1000 \mathrm{~g}$ for $10 \mathrm{~min}$ at $4^{\circ} \mathrm{C}$ and stored at $-80^{\circ} \mathrm{C}$ until analysis. After plasma separation, the white buffy layer (leucocytes) was removed and the packed cells washed twice with physiological saline. A known volume of erythrocytes was lysed in 4 volumes of ice-cold HPLC-grade water and then centrifuged at $3000 \boldsymbol{g}$ for $10 \mathrm{~min}$ at $4^{\circ} \mathrm{C}$. The supernatant was collected and stored at $-80^{\circ} \mathrm{C}$ until analysis.

Graphite furnace atomic absorption spectroscopy was used to determine the concentration of Se in plasma ${ }^{(22)}$. GPX activity in erythrocytes was measured using the spectrophotometric method described by Paglia and Valentine ${ }^{(23)}$.

\section{Statistical analyses}

Data are expressed as means with their standard deviation. Comparison between parameters of breast cancer patients and controls was performed using the independent $t$ test. A value $P<0.05$ was considered significant. All statistical analyses were conducted using the Statistical Package for the Social Sciences (SPSS for Windows) statistical software package version 11 (SPSS Inc., Chicago, IL, USA).

\section{Results}

Table 1 presents details of the study population in terms of age, weight, BMI, age at first pregnancy, age at onset of

Table 1 Description of the study population: Iranian breast cancer patients and controls

\begin{tabular}{|c|c|c|c|c|c|c|}
\hline \multirow[b]{2}{*}{ Characteristic } & \multirow[b]{2}{*}{$n$} & \multicolumn{2}{|c|}{ Cases } & \multicolumn{2}{|c|}{ Controls } & \multirow[b]{2}{*}{ Significance ( $t$ test) } \\
\hline & & Mean & SD & Mean & SD & \\
\hline Age (years) & 45 & $45 \cdot 0$ & $9 \cdot 0$ & $44 \cdot 3$ & $8 \cdot 7$ & NS \\
\hline Weight (kg) & 45 & $64 \cdot 8$ & $12 \cdot 2$ & $70 \cdot 1$ & $9 \cdot 5$ & $P<0.02$ \\
\hline Height (cm) & 45 & $156 \cdot 5$ & $5 \cdot 3$ & $157 \cdot 4$ & $4 \cdot 8$ & NS \\
\hline BMI $\left(\mathrm{kg} / \mathrm{m}^{2}\right)$ & 45 & $26 \cdot 5$ & $5 \cdot 0$ & $28 \cdot 4$ & $3 \cdot 7$ & $P<0.05$ \\
\hline Age at first pregnancy (years) & 41 & $22 \cdot 0$ & $6 \cdot 0$ & $18 \cdot 5$ & $3 \cdot 6$ & $P<0.002$ \\
\hline Age at menarche onset (years) & 45 & $13 \cdot 3$ & $1 \cdot 6$ & $13 \cdot 3$ & $1 \cdot 1$ & NS \\
\hline Number of children & 41 & $3 \cdot 7$ & $1 \cdot 8$ & $3 \cdot 8$ & $1 \cdot 8$ & NS \\
\hline Age at menopause onset (years) & 11 & $48 \cdot 4$ & $4 \cdot 5$ & $48 \cdot 3$ & $4 \cdot 0$ & NS \\
\hline
\end{tabular}


Table 2 Plasma selenium and erythrocyte glutathione peroxidase (GPX) activity in Iranian breast cancer patients and controls

\begin{tabular}{|c|c|c|c|c|c|c|}
\hline \multirow[b]{2}{*}{ Parameter } & \multirow[b]{2}{*}{$n$} & \multicolumn{2}{|c|}{ Cases } & \multicolumn{2}{|c|}{ Controls } & \multirow[b]{2}{*}{ Significance ( $t$ test) } \\
\hline & & Mean & SD & Mean & SD & \\
\hline Plasma Se $(\mu \mathrm{g} / \mathrm{l})$ & 45 & $132 \cdot 15$ & $35 \cdot 37$ & $138 \cdot 40$ & $40 \cdot 36$ & NS \\
\hline Erythrocyte GPX (U/g Hb) & 45 & $24 \cdot 81$ & $11 \cdot 66$ & $20 \cdot 29$ & $4 \cdot 24$ & $P<0.01$ \\
\hline
\end{tabular}

Table 3 Plasma selenium and erythrocyte glutathione peroxidase (GPX) activity in Iranian breast cancer patients according to disease stage

\begin{tabular}{|c|c|c|c|c|c|}
\hline \multirow[b]{2}{*}{ Clinical stage } & \multirow[b]{2}{*}{$n$} & \multicolumn{2}{|c|}{ Plasma Se $(\mu \mathrm{g} / \mathrm{l})$} & \multicolumn{2}{|c|}{$\begin{array}{c}\text { Erythrocyte GPX } \\
(\mathrm{U} / \mathrm{g} \mathrm{Hb})\end{array}$} \\
\hline & & Mean & SD & Mean & $\mathrm{SD}$ \\
\hline Stage & 8 & $120 \cdot 87$ & $36 \cdot 03$ & $25 \cdot 33$ & $17 \cdot 29$ \\
\hline Stage II & 23 & $133 \cdot 65$ & $30 \cdot 60$ & $24 \cdot 91$ & $11 \cdot 39$ \\
\hline Stage III & 14 & $125 \cdot 07$ & $46 \cdot 52$ & $24 \cdot 36$ & 8.90 \\
\hline Significance ( & & \multicolumn{2}{|c|}{ NS } & \multicolumn{2}{|c|}{ NS } \\
\hline
\end{tabular}

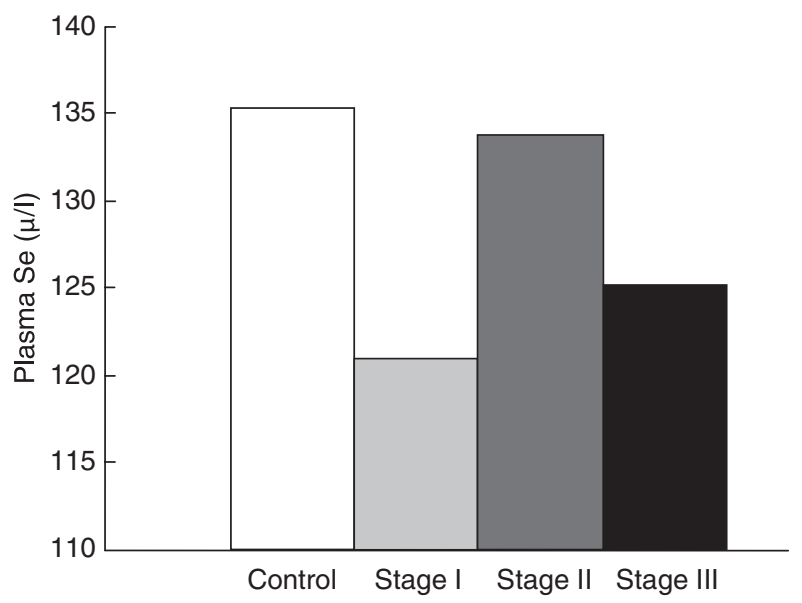

Fig. 1 Plasma selenium concentration in Iranian breast cancer patients according to disease stage

menarche, number of children and age at onset of menopause. The table shows that weight, BMI and age at first pregnancy were significantly different between the two groups $(P<0 \cdot 05)$.

The mean plasma Se concentration and erythrocyte GPX activity of the breast cancer patients and the control subjects are presented in Table 2 . No significant difference was observed in Se levels of the two groups, but patients with breast cancer had a significantly higher erythrocyte GPX activity than did the control group $(P<0 \cdot 01)$.

According to the WHO classification, tumours were classified as stage I (eight patients), stage II (twenty-three patients) and stage III (fourteen patients). As Table 3, Fig. 1 and Fig. 2 show, there were no significant differences in plasma Se concentration and erythrocyte GPX activity between these disease subgroups.

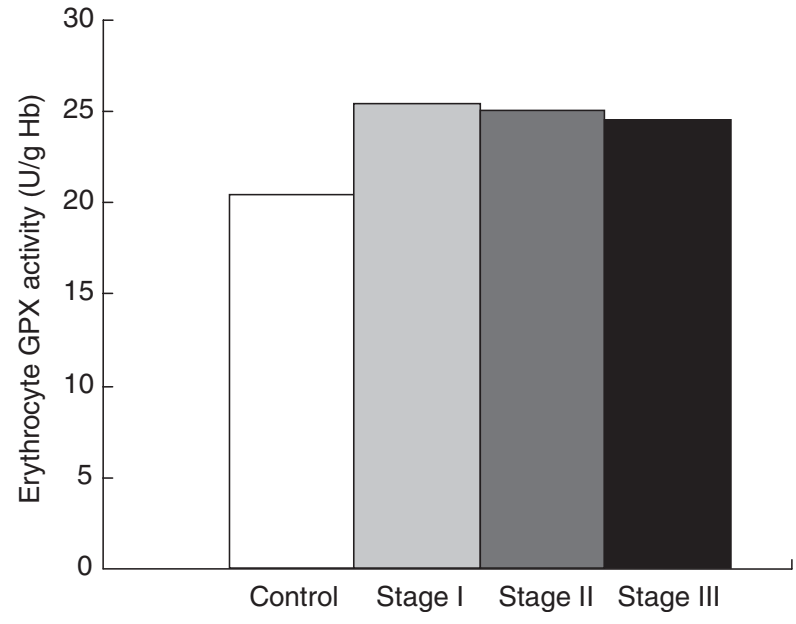

Fig. 2 Erythrocyte glutathione peroxidase (GPX) activity in Iranian breast cancer patients according to disease stage

\section{Discussion}

In recent years, many studies have shown that $\mathrm{Se}$ is a potent protective nutrient for some forms of cancer. Studies have also shown that breast cancer patients present serious disturbance in the status of trace elements, especially those involved in oxidant systems. Oxidative stress produced through either increased free radical generation and/or a decreased antioxidant level in the target cells and tissues has been suggested to play an important role in carcinogenesis ${ }^{(24)}$. As far as breast cancer is concerned, enhanced oxidative stress in tissues and serum has been reported ${ }^{(25-27)}$; however, the aetiology of the majority of human breast cancer is still unclear. With regard to human tumours, the limited data available concerning serum levels of Se do not show similar trends. The results of the present study showed lower plasma Se levels in breast cancer patients compared with control subjects; however, the difference was not statistically significant. Also, no significant reduction in plasma Se was observed across three breast cancer disease stages. This may be due to the small numbers of patients in these subgroups.

A case-control study conducted in Spain revealed that the mean serum Se concentration was $81 \cdot 1 \mu \mathrm{g} / 1$ in women with breast cancer and $98.5 \mu \mathrm{g} / 1$ in women with non-tumoural disease $(P<0 \cdot 001)$, but the difference between two subgroups (stage I-II and stage III-IV) was not significant ${ }^{(28)}$. Gupta et al. ${ }^{(29)}$ also found that plasma 
Se concentration was decreased in patients with breast cancer but that Se level decreased with the progress of disease. Similar results were found by Piccinnini et al. ${ }^{(30)}$ and Krsnjavi and Beker ${ }^{(31)}$. Willett et al. $^{(32)}$ reported that low serum Se levels existed before the cancers developed, thereby increasing a person's risk of developing cancer. However, the results obtained for Se in the present study are similar to others in that breast cancer was not found to be influenced by Se status; so it has been suggested that, in contrast to men, women do not appear to be as sensitive to $\mathrm{Se}^{(17,18,33-35)}$.

It must be borne in mind that variability of serum Se may be due to factors other than cancer such as the Se contents of soil and products grown in a geographical area, age, sex, BMI, dietary habits, lifestyle (smoking etc.), concurrent disease and medications.

On the other hand, these studies are methodologically complex, and at present various types of investigation (prospective, environmental, epidemiological and casecontrol) have failed to provide conclusive results. So the explanation for these differences cannot be made at this time.

The products of lipid peroxidation reactions in the serum and tissue of breast cancer patients have been reported by Punnonen et al. ${ }^{(36)}$. Higher $\mathrm{H}_{2} \mathrm{O}_{2}$ production in breast cancer under oxidative stress conditions, and the increased concentrations of free radicals and reactive oxygen species may lead to damage of most biomolecules. Some enzymes such as GPX are considered antioxidant enzymes, since it is involved in direct elimination of these products. Se is a component of GPX, and acts as antitumour agent. The decrease in plasma Se may be the result of increased activity of GPX or increased tumoural mass, which in turn may increase the amount of free radicals in the tumoural tissue. These free radicals may attract greater amounts of Se through electrophilic mechanisms which results in the reduction of Se in plasma.

The present findings showed a highly significant elevation in erythrocyte GPX activity in breast cancer patients $(P<0 \cdot 01)$ compared with the control group. This may be due to the response to higher free radical production in breast cancer patients. This result is in good agreement with many other authors. Ray et al. ${ }^{(37)}$ reported significantly increased GPX activity in breast cancer patients and significantly higher GPX activity in all subgroups (stage II, III and IV). Findings by Seven et al. ${ }^{\text {(38) }}$ also suggest that there is a significant increase in erythrocyte GPX concentration $(P<0 \cdot 01)$ in breast cancer patients compared with patients with benign breast disease.

We suggest that patients with breast cancer have increased GPX activity due to increased formation of reactive oxygen species that causes increase in the antioxidant enzymes such as GPX, to improve the resistance of neoplastic cells to toxicity associated with tumour promotion. On the other hand, in our population study because Se deficiency was not a problem and its concentration was in the normal range, it was possible for cells to increase GPX.

\section{Conclusion}

Although Se deficiency was not a problem in the present study, it remains unclear whether low serum Se levels are induced by cancer or if they are a risk factor for cancer. If a low Se level is a risk factor for cancer, then Se administration may have a preventive effect.

\section{Acknowledgements}

Conflicts of interest: The authors declare that they have no conflicts of interest, financial, academic or otherwise.

Sources of funding: Funding through Shiraz University of Medical Sciences supported this study.

Author contributions: M.M. conceived and conducted the trial. M.M., M.H.E. and A.T. contributed to the study protocol; A.T. provided constant assistance at all stages of data gathering; M.M. and M.H.E. carried out the laboratory work. M.M. and A.R.F. conducted the statistical analysis; M.M., M.H.E. and A.T. contributed to the design of the analysis and interpretation of the results. M.M. drafted the first version of the manuscript and revised it with cooperation from M.H.E.

Acknowledgments: The authors wish to thank to the participants for their compliance and patience, and the Gasteroentrohepatic Research Center for facilitating the biomedical tests.

\section{References}

1. McPherson K, Steel CM \& Dixon JM (2000) Breast cancer epidemiology, risk factors, and genetics. BMJ 321, 624-628.

2. Kahan E, Ibrahim AS, El Najjar K, Ron E, Al-Agha H, Polliack A \& El-Bolkainy MN (1997) Cancer patterns in the Middle East - special report from the Middle East Cancer Society. Acta Oncol 36, 631-636.

3. Harirchi I, Karbakhsh M, Kashefi A \& Momtahen A (2004) Breast cancer in Iran: results of a multi-center study. Asian Pac J Cancer Prev 5, 24-27.

4. Patrick L (2004) Selenium biochemistry and cancer: a review of the literature. Altern Med Rev 9, 239-258.

5. Ganther HE (1999) Selenium metabolism, selenoproteins and mechanisms of cancer prevention: complexities with thioredoxin reductase. Carcinogenesis 20, 1657-1666.

6. Rayman MP (2000) The importance of selenium to human health. Lancet 356, 233-241.

7. Clement IP (1998) Lessons from basic research in selenium and cancer prevention. J Nutr 128, 1845-1854.

8. El-Bayoumy K (editor) (1991) The Role of Selenium in Cancer Prevention. Philadelphia, PA: Lippincott.

9. Ip C (1986) Selenium and experimental cancer. Ann Clin Res 18, 22-29.

10. Clark LC, Combs GF, Turnbull BW et al. (1996) Effects of selenium supplementation for cancer prevention in patients with carcinoma of the skin. JAMA 276, 1957-1985. 
11. Yoshizawa K, Willett WC, Morris SJ, Stampfer MJ, Spiegelman D, Rimm EB \& Giovannucci E (1998) Study of prediagnostic selenium level in toenail and the risk of advanced prostate cancer. J Natl Cancer Inst 90, 1184-1185.

12. Brooks JD, Metter EJ, Chan DW, Sokoll LJ, Landis P, Nelson WG, Muller D, Andres R \& Carter HB (2001) Plasma selenium level before diagnosis and the risk of prostate cancer development. J Urol 166, 2034-2038.

13. Knekt P, Marniemi J, Teppo L, Heliovaara M \& Aromaa A (1998) Is low selenium status a risk factor for lung cancer? Am J Epidemiol 148, 975-982.

14. McConnell KP, Jager RM, Bland KI \& Blotcky AJ (1980) The relationship of dietary selenium and breast cancer. $J$ Surg Oncol 15, 67-70.

15. Garland M, Morris JS, Stampfer MJ, Colditz GA, Spate VL, Baskett CK, Rosner B, Speizer FE, Willett WC \& Hunter DJ (1995) Prospective study of toenail selenium levels and cancer among women. J Natl Cancer Inst 87, 497-505.

16. Garland M, Willett WC, Manson JE \& Hunter DJ (1993) Antioxidant micronutrients and breast cancer. $\mathrm{J} \mathrm{Am}$ Coll Nutr 12, 400-411.

17. Hunter DJ, Morris JS, Stampfer MJ, Colditz GA, Speizer FE \& Willett WC (1990) A prospective study of selenium status and breast cancer risk. JAMA 264, 1128-1131.

18. Ghadirian P, Maisonneuve P, Perret C, Kennedy G, Boyle P, Krewski D \& Lacroix A (2000) A case-control study of toenail selenium and cancer of the breast, colon, and prostate. Cancer Detect Prev 24, 305-313.

19. Floyd RA (1990) Role of oxygen free radicals in carcinogenesis and brain ischemia. FASEB J 4, 2587-2597.

20. Arthur JR (2000) The glutathione peroxidases. Cell Mol Life Sci 57, 1825-1835.

21. Townsend CM, Beauchamp RD, Evers BM \& Mattox K (editors) (2004) Sabiston Textbook of Surgery, 17th ed. Philadelphia, PA: WB Saunders.

22. Sheehan TM \& Halls DJ (1999) Measurement of selenium in clinical specimens. Ann Clin Biochem 36, 301-315.

23. Paglia DE \& Valentine WN (1967) Studies on the quantitative and qualitative characterization of erythrocyte glutathione peroxidase. J Lab Clin Med 70, 158-169.

24. Ames BN (1983) Dietary carcinogens and anticarcinogens: oxygen radicals and degenerative diseases. Science $\mathbf{2 2 1}$, 1256-1264

25. Wang M, Dhingra K, Hittelman WN, Liehr JG, de Andrade M \& Li D (1996) Lipid peroxidation-induced putative
malondialdehyde-DNA adducts in human breast tissues. Cancer Epidemiol Biomarkers Prev 5, 705-710.

26. Nelson RL (1992) Dietary iron and colorectal cancer risk. Free Radic Biol Med 12, 161-168.

27. Boyd NF \& McGuire V (1991) The possible role of lipid peroxidation in breast cancer risk. Free Radic Biol Med 10, 185-190.

28. Lopez-Saez JB, Senra-Varela A \& Pousa-Estevez L (2003) Selenium in breast cancer. Oncology 64, 227-231.

29. Gupta S, Narang R, Krishnaswami K \& Yadav S (1994) Plasma selenium level in cancer patients. Indian J Cancer 31, 192-197.

30. Piccinini L, Borella P, Bargellini A, Medici IC \& Zoboli A (1996) A case-control study on selenium, zinc, and copper in plasma and hair of subjects affected by breast and lung cancer. Biol Trace Elem Res 51, 23-30.

31. Krsnjavi H \& Beker D (1990) Selenium in serum as a possible parameter for assessment of breast disease. Breast Cancer Res Treat 16, 57-61.

32. Willett WC, Polk BF, Morris JS, Stampfer MJ, Pressel S, Rosner B, Taylor JO, Schneider K \& Hames CG (1983) Prediagnostic serum selenium and risk of cancer. Lancet $\mathbf{2}$, 130-134.

33. Van den Brandt PA, Goldbohm RA \& van't Veer P (1994) Toenail selenium levels and the risk of breast cancer. $A m J$ Epidemiol 140, 20-26.

34. Van't Veer P, Van der Wielen RP, Kok FJ, Hermus RJ \& Sturmans F (1990) Selenium in diet, blood, and toenails in relation to breast cancer: a case-control study. $A m J$ Epidemiol 131, 987-994.

35. Van Noord PA, Collette HJ, Maas MJ \& de Waard F (1987) Selenium levels in nails of premenopausal breast cancer patients assessed prediagnostically in a cohort-nested case-referent study among women screened in the DOM project. Int J Epidemiol 16, 318-322.

36. Punnonen K, Ahotupa M, Asaishi K, Hyöty M, Kudo R \& Punnonen R (1994) Antioxidant enzyme activities and oxidative stress in human breast cancer. J Cancer Res Clin Oncol 120, 374-377.

37. Ray G, Batra S, Shukla NK, Deo S, Raina V, Ashok S \& Husain SA (2000) Lipid peroxidation, free radical production and antioxidant status in breast cancer. Breast Cancer Res Treat 59, 163-170.

38. Seven A, Erbil Y, Seven R, Inci F, Gülyaşar T, Barutçu B \& Candan G (1998) Breast cancer and benign breast disease patients evaluated in relation to oxidative stress. Cancer Biochem Biophys 16, 333-345. 